\title{
Understanding breast-cancer patients' perceptions: Health information-seeking behaviour and passive information receipt
}

\author{
Daniel R. Longo, ${ }^{\star}$ Bin Ge, ${ }^{\star \star}$ M. Elise Radina, ${ }^{\star \star \star}$ Allen Greiner, ${ }^{\star \star \star \star}$ \\ Casey D. Williams, ${ }^{\star \star \star \star \star \star}$ Gregory S. Longo, ${ }^{\star \star \star \star \star \star}$ Dawne M. Mouzon, ${ }^{\star \star \star \star \star \star \star}$ \\ Ana Natale-Pereira ${ }^{\star \star \star \star \star \star \star \star}$ and Debbie Salas-Lopez ${ }^{\star \star \star \star \star \star \star \star \star \star}$
}

Received (in revised form): 12th January, 2009

*Department of Family Medicine, Virginia Commonwealth University School of Medicine, MCV Campus, West Hospital, 10th Floor, Room 1012, 1200 East Broad Street, P.O. Box 980251, Richmond, VA 23298-0251, USA. Tel: +1 804828 9652; Fax +1804827 0227; E-mail drlongo@vcu.edu

${ }^{\star \star}$ Medical Research Office, N519 Medical Sciences Bldg., University of Missouri, Columbia, MO 65212, USA; Tel: +1 573882 0998; E-mail geb@health.missouri.edu ${ }^{* \star \star}$ Family Studies and Social Work, 101 McGuffey Hall, Miami University, Oxford, $\mathrm{OH}$ 45056, USA; Tel: +1 513529 2323; Fax +1 513529 6468;

E-mail radiname@muohio.edu

${ }^{* * \star *}$ University of Kansas, Family Medicine, Mail Stop 4010, 3901 Rainbow Blvd., Kansas City, KS 66160, USA; Tel: +1 913588 1908; E-mail agreiner@kumc.edu

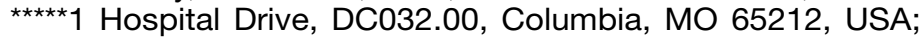

E-mail williamscd@health.missouri.edu

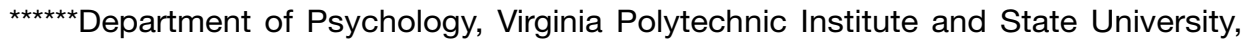
109 Williams Hall, Blacksburg, VA 23226, USA; Tel: +1 540231 8036;

Fax +1540 231 3652; E-mail glongo@vt.edu

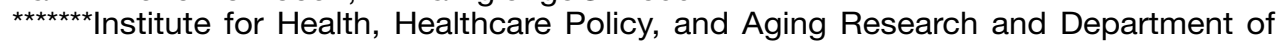
Sociology, Rutgers University, 30 College Avenue, New Brunswick, NJ 08901, USA; Tel: +1 732932 4647; Fax +1 7329320069

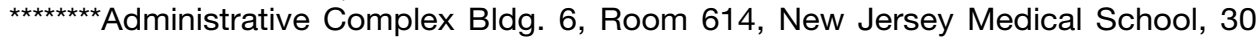
Bergen Street, Newark, NJ 07107, USA.

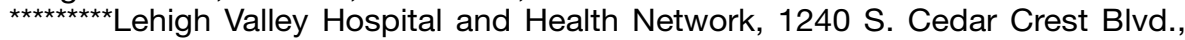
JDMCC Suite 410, Allentown, PA 18105, USA; Tel: +1 610402 1654;

Fax +1610402 1675 .

Journal of Communication in Healthcare

Vol. 2 No. 2, pp. 184-206 (C) Henry Stewart Publications, (C) Henry Stew
$1753-8068$
Daniel R. Longo is Professor and Director of Research and the Co-director of the Virginia Ambulatory Care Outcomes Research Network in the Department of Family Medicine at Virginia Commonwealth University (VCU), Richmond, VA. He was Professor of Family and Community Medicine at University of Missouri-Columbia (MU), at the time of this study. As Director of the Grant Generating Project Fellowship, Daniel has trained more than 100 family medicine faculty members from university and community-based family medicine programmes in the USA and Canada in grantsmanship skills aimed at increasing family medicine research capacity; $\mathrm{He}$ is also currently working on development of research mentorship training seminars for the North American Primary Care Research Group. Daniel is a member of the VCU Academy of Mentors. He is the past publisher of Health Services Research, immediate past editor of the International Journal of Tobacco Induced Diseases and a former member of the first executive committee of the Society for Prevention of Tobacco Induced Diseases. Daniel is a member of the editorial boards of the Journal of Healthcare Finance and the Health Expectations.

Bin $\mathrm{Ge}$ is a statistician in the Office of Medical Research biostatistics group at MU, since 2002. 
She was previously a Statistician at Kansas University Medical Center in Kansas City, and a Research Specialist at University of Wisconsin, Madison. She earned her medical doctorate at China Medical University in Shenyang, People's Republic of China, and was a medical intern and endocrinology specialist at Shenyang Medical College Central Hospital. In addition to the present study, her recent work at MU includes a number of research projects in the areas of chronic disease, rheumatology and patient safety.

M. Elise Radina was Post-doctoral Fellow in the Department of Family and Community Medicine at MU. She is currently Assistant Professor and Director of the Undergraduate Family Studies Program in the Department of Family Studies and Social Work at Miami University. Her current research focuses on perceived changes in family quality of life following breast-cancer diagnosis among survivors, their adult children, and their mothers. This work is currently funded in part by the Cincinnati Affiliate of Susan G. Komen for the Cure.

Allen Greiner is the Assistant Professor of Family Medicine and Preventive Medicine at University of Kansas Medical Center, Kansas City, Kansas. He is Medical Director/Health Officer for the Health Department of the Unified Government of Wyandotte County/Kansas City. Allen is a member of the Board of Directors of the Community Health Council of Wyandotte County, the Duschene Clinic, and Southwest Boulevard Family Care. He is Faculty Co-advisor for the JayDoc Free Clinic, and for the medical school's Community Leadership track. He directs the Rural Primary Care Practice and Research Program and linked Kansas Physicians Engaged in Prevention Research Network, is a National Institutes of Health Health Disparities Scholar, and was a 2004 Kemper Fellowship Award winner.

Casey D. Williams was Research Fellow in the Department of Family and Community Medicine at University of Missouri School of Medicine during this project. A graduate of the Columbia, Missouri-based university and medical school, Casey is currently a resident physician in the Department of Family and Community Medicine, practising at the university hospital and clinics.

Gregory S. Longo, is an honours graduate of Wabash College (Indiana) where he received (second place) the John N. Mills Prize in Religion. He was a research assistant in the Department of Family Medicine, MU School of Medicine, when the research was conducted. $\mathrm{He}$ currently is a doctoral student in the Department of Psychology at Virginia Polytechnic Institute and State University, conducting research in the field of psychology of religion, specifically examining how religion plays a protective role against child maltreatment as well as how to best measure religiosity.

Dawne M. Mouzon was Research Associate in the Division of Academic Medicine, Geriatrics, and Community Programs at University of Medicine and Dentistry of New Jersey (UMDNJ), New Jersey Medical School during this project. She is currently a doctoral student in medical sociology at the Institute for Health, Healthcare Policy, and Aging Research and the Department of Sociology at Rutgers University. She is also funded as a National Institute of Mental Health Minority Fellow with the American Sociological Association.

Ana Natale-Pereira is Assistant Professor in Academic Medicine, Geriatrics, and Community Programs, New Jersey Medical School, UMDNJ.

Debbie Salas-Lopez is Chair of the Department of Medicine, Vice Chair of Clinical Programs and Chief of the Division of General Internal Medicine in the Department of Medicine at Lehigh Valley Hospital and Health Network in Allentown, Pennsylvania. She is Associate Professor of Medicine at Penn State College of 
Medicine. She completed medical school and a residency in internal medicine at UMDNJ and obtained a master's degree in health policy and administration at the School of Public Health, Rutgers University, and UMDNJ. Debbie is currently a Fellow of the American College of Physicians, and a member of the Northeast Consortium on Cultural Competency and Medical Education, and she participated in the legislative process that resulted in a law requiring cultural competency as a condition of licensure in the State of New Jersey. Debbie serves on National Institutes of Health study sections with a special focus on health literacy and access to care. She is a nationally recognised speaker and educator in the area of cultural competency and medical interpretation.

\section{Abstract}

It is critical to understand patients' information use from the patient perspective, especially when patients are from different cultures and levels of health literacy. A cross-sectional survey supplemented with interviews of breast cancer survivors including both Latina and nonLatina women was undertaken. Subjects were classified as active information seekers, passive information receivers, and/or users of information. Subjects were further classified by stage of information use, progressing from unawareness or awareness of available information to use or non-use of information to make health decisions. Information sources used and use patterns were examined. Most were active information seekers; many were also passive receivers. Healthcare providers remain the primary information source. Interpersonal communication was far more often cited than either the internet or traditional print and broadcast media. Important cross-cultural differences were found. This study provides insight into how patients use actively sought and passively received information. Despite dramatic growth of the internet and other new media, healthcare providers currently remain keys to health information. Findings may help develop more successful communication strategies when viewed in light of the National Cancer Institute's 'Making Health Communication Programs Work' and the four stages it proposes. It is hoped that future work will focus on evidence-based methods to improve health communication, especially for vulnerable populations. A major lesson learned is the importance of understanding where patients decided to seek information outside the traditional provideroriented approach taken in many health education programmes.

Keywords: health communication, breast cancer, patient preferences, health information

\section{INTRODUCTION}

Breast cancer is the most frequent cancer in women worldwide, with the highest incidence rates in North America. ${ }^{1}$ Breast cancer is the most frequently diagnosed non-skin cancer and is second only to lung cancer as the leading cause of cancer deaths in women in the USA, with 200,000 women developing breast cancer each year. $^{2-4}$ In the USA, the incidence of breast cancer, but also the five-year survival rate, is lower for Latina and African-American women than for Caucasian women. ${ }^{5-8}$ Latina ethnicity is associated with decreased survival time ${ }^{9}$ and Latina women are more likely than Caucasian women to be diagnosed with advanced-stage disease. ${ }^{10,11}$

Breast cancer is one of the most common health topics on the internet; ${ }^{12}$ however, to date there are relatively few evaluations of the quality, accuracy, or utilisation of internet information on breast cancer. ${ }^{13-18}$ Currently, most internet information is written at a university reading level. ${ }^{19}$ Information may also be inconsistent across websites, and patients may have to visit several sites before finding answers to their questions. ${ }^{20}$ 
Latinas face additional barriers to access and use of internet-based information. While one cannot assume that all Latinas living in English-speaking countries are primarily Spanish-speaking, examining internet-based health information that is available in Spanish helps to gain a clearer picture of what types of information may be accessed by Latinas generally. Berland and colleagues found that using simple search terms for information on Spanish websites is inefficient, and that coverage of information on Spanish sites is often poor. ${ }^{21}$ Like English sites, Spanish sites also require an advanced reading level, ${ }^{22}$ which may limit the use of these sites by Latinas with limited formal education. Latinas are also disproportionately affected by the 'digital divide', a lack of internet access for people with lower incomes. For example, in the USA, roughly 5 per cent of Latino/as who make US $\$ 15,000$ or less annually use the internet. ${ }^{23}$

\section{Health literacy and cross-cultural communication}

To compound the complexity of these issues are those of health literacy and cross-cultural communication that have been recognised as vital variables in the ability of a patient to understand and use health information. For example, the Institute of Medicine has recognised in its work the major concern posed by these issues. ${ }^{24}$ This is supported by studies that show that 16-38 per cent of adults are illiterate or have low literacy skills and, therefore, have difficulties in accessing and using health information. ${ }^{25}$ Despite the widespread use of the internet, adults with low literacy may encounter problems due to health literacy when searching the internet for health information, in part because most health websites require at least a high-school reading proficiency for optimal access. ${ }^{26}$ Nonetheless, there is the hope that 'healthcare providers can en- hance the effectiveness and efficiency of the care they provide by recognizing their patient's health literacy ${ }^{27}$ as well as the many issues that could be resolved if differences in cross-cultural communication are addressed. ${ }^{28,29}$

Most current literature on cancer information-gathering behaviour focuses on 'active information seeking' from sources such as the internet or healthcare organisations (eg American Cancer Society). While there is some understanding about the degree to which healthcare decisions are influenced by active or intentional information-seeking, there is a paucity of studies that explicitly examine 'passive receipt' of information - also referred to as 'scanning' and 'incidental' or 'mere' exposure to information - in the course of daily activities such as watching television or reading popular magazines. ${ }^{30-32}$ There is presently little evidence on the combined influence of actively sought and passively received cancer information on patients' healthcare decisions. ${ }^{33}$ Most literature on passive cancer information receipt focuses on 'typical' passive sources such as television, radio, or newspapers; however, Shim and colleagues postulate that both active and passive receipt of information can occur from all information sources, with information 'scanning' especially common with respect to mammography. ${ }^{34}$ Little is known about what type of information most empowers behavioural change, ${ }^{35}$ how patients use the many sources and types of information they encounter in information seeking and use, and in what ways patients are influenced by readily accessible information on the internet that was previously available only from healthcare providers.

\section{The Longo model}

The trend toward healthcare consumerism, coupled with the information explosion and an emphasis on patient 
centredness, ${ }^{36}$ means patients take a greater role in learning about their disease and making decisions about treatment and management. ${ }^{37-39}$ This concept of patient centredness is foundational to the 'Expanded Conceptual Model of Health Information Seeking Behaviours and the Use of Information for Healthcare Decisions' (Figure 1) proposed by Longo. $^{40}$ The approach adapts medical care to current social norms and communication patterns, and has been linked to improved patient satisfaction and lowered symptom burden. ${ }^{41-43}$ From this perspective, assessing and meeting patients' health information needs is not only a critical component of a treatment and management plan, ${ }^{44,45}$ but also a major factor enabling patients to become informed healthcare decision-makers and effective partners in their care. ${ }^{46}$

The Longo model, initially proposed in Health Expectations and further revised in the present paper to take into account more explicitly health literacy and crosscultural communication concerns, further fills gaps in the current literature by postulating that consumers are not just active 'information seekers' as most of the health communication literature suggests, but that there is a major and vital complementary channel of passive health information receipt. In addition to actively seeking health information, individuals passively receive such information in a variety of venues. The combination of active and passive information receipt, along with individual patient characteristics, influences information use and represents a far more comprehensive and accurate model of consumer health information seeking behaviours, as well as a model to examine how consumers use information to make healthcare decisions. This model is one of two models identified by the National Cancer Institute $(\mathrm{NCI})^{47}$ that explain this phenomenon, and the expanded Longo model is the only model that explicitly classifies patients as active seekers and/or passive receivers of information, taking into account various stages of information access, use and decision-making.

Following the Longo model in the present study, whatever a patient referred to as 'information' was identified as such, as input from prior in-depth interviews and focus groups made clear that exchanges such as informal discussions with friends, relatives and neighbours are considered 'health information' as much as medical provider and media information sources.

This study's communication objectives are to: (1) identify the most frequent information sources used by breast-cancer patients; (2) understand what proportion of patients actively seek and/or passively receive information from these sources; (3) understand the extent to which the revised Longo conceptual model helps explain the interplay of active and passive information receipt and the influence of contextual and personal variables on outcomes; (4) determine what proportion of patients indicate they are able to use available health information; (5) determine what proportion report using this information in making healthcare decisions, and (6) understand differences between Latinas and non-Latinas relative to the above objectives. It is expected that the answers to these objectives will provide the basis for more effective communication programmes for women with breast cancer following the National Cancer Institute's 'Making Health Communication Programs Work' and the four stages it proposes.

\section{METHODS}

A total of 158 breast-cancer survivors were surveyed using pre-tested questions 
Variables Influencing Patient/Consumer Phase of Information Seeking Behaviour and Information Use

Contextual

- Health status

- Healthcare structure

- Delivery of care

- Information environment factors

- Information seeking for self, family member, or friend either at risk or with current medical problem

- Cross-cultural communication

\section{Personal}

- Demographic factors

- Socioeconomic factors

- Health history

- Genetics

- Family medical history

- Education

- Culture

- Language

- Attitudes, intentions, behaviours

- Current health status

- Health literacy
Figure 1 Expanded conceptual model of health information seeking behaviours and the use of information for healthcare decisions
Phases of Information Use: Active Information Seeking

1. Patient/consumer is not aware of available information in traditional mass media, new media, or through personal interactions.

2. Patient/consumer is aware of available information in traditional mass media, new media, or through personal interactions but does not attempt to access it

3. Patient/consumer is aware of available information in traditional mass media, new media, or through personal interactions and attempts to access it.

4. Patient/consumer accesses the information in traditional mass media, new media, or through personal interactions but is not able to use it.

5. Patient/consumer accesses the information in traditional mass media, new media, or through personal interactions and is able to use it.

6. Patient/consumer accesses the information in traditional mass media, new media, or through personal interactions but does not use it to make personal healthcare decisions .

7. Patient/consumer accesses the information in traditional mass media, new media, or through personal interactions and uses it to make personal health care decisions
Phases of Information Use: Passive Receipt of Information

1. Consumer/patient does not receive information through traditional mass media, new media, or personal interactions.

2. Consumer/patient receives information through traditional mass media, new media, or personal interactions.

3. Consumer/patient receives information through traditional mass media, new media, or personal interactions but does not use the information.

4. Consumer/patient receives information through traditional mass media, new media, or personal interactions and uses the information.

5. Consumer/patient receives information through traditional mass media, new media, or personal interactions but does not use it to make personal health care decisions.

6. Consumer/patient receives information through traditional mass media, new media, or personal interactions and uses it to make personal health care decisions.

Patient/Consumer Outcomes:

- Empowerment/Locus of Control

- Satisfaction

- Activities of Daily Living

- Health Outcomes 
Table 1: Demographic characteristics of study subjects $\star$

\begin{tabular}{|c|c|c|c|c|c|}
\hline & \multicolumn{2}{|c|}{ Latina $(n=40)$} & \multicolumn{3}{|c|}{ Non-Latina $(n=118)$} \\
\hline & $n$ & $(\%)$ & $n$ & $(\%)$ & $p$-value $e^{\dagger}$ \\
\hline Stage of cancer at diagnosis: & & & & & 0.0277 \\
\hline Stage 0 & 4 & 10.0 & 12 & 10.3 & \\
\hline Stage 1 & 11 & 27.5 & 48 & 41.0 & \\
\hline Stage 2 & 10 & 25.0 & 37 & 31.6 & \\
\hline Stage 3 & 9 & 22.5 & 11 & 9.4 & \\
\hline Stage 4 & 5 & 12.5 & 4 & 3.4 & \\
\hline Don't know & 1 & 2.5 & 5 & 4.3 & \\
\hline Phase of treatment at time of survey completion: & & & & & $<0.0001$ \\
\hline Phase 2 (evaluation) & 1 & 2.6 & 0 & 0.0 & \\
\hline Phase 3 (undergoing treatment) & 18 & 47.4 & 12 & 10.9 & \\
\hline Phase 4 (remission or reoccurrence) & 19 & 50.0 & 95 & 86.4 & \\
\hline Phase 5 (long term) & 0 & 0.0 & 3 & 2.7 & \\
\hline Ethnic/racial background: & & & & & $<0.0001$ \\
\hline African-American/Black & 0 & 0.0 & 9 & 7.6 & \\
\hline Asian/Pacific Islander & 0 & 0.0 & 1 & 0.8 & \\
\hline Caucasian/White & 0 & 0.0 & 106 & 89.8 & \\
\hline Latina & 38 & 95.0 & 0 & 0.0 & \\
\hline Multi-ethnic & 2 & 5.0 & 2 & 1.7 & \\
\hline Language: & & & & & $<0.0001$ \\
\hline Spanish only & 23 & 57.5 & 0 & 0.0 & \\
\hline English or bilingual & 17 & 42.5 & 118 & 100.0 & \\
\hline Marital status: & & & & & 0.0479 \\
\hline Married/living as married & 28 & 70.0 & 86 & 72.9 & \\
\hline Divorced & 3 & 7.5 & 15 & 12.7 & \\
\hline Separated & 4 & 10.0 & 1 & 0.8 & \\
\hline Widowed & 2 & 5.0 & 10 & 8.5 & \\
\hline Single, never married & 3 & 7.5 & 6 & 5.1 & \\
\hline Education: & & & & & 0.0005 \\
\hline 8th grade or less & 5 & 12.8 & 3 & 2.5 & \\
\hline Some high school & 8 & 20.5 & 5 & 4.2 & \\
\hline High school diploma or GED & 7 & 17.9 & 23 & 19.5 & \\
\hline Vocational school or some college & 12 & 30.8 & 34 & 28.8 & \\
\hline College degree & 1 & 2.6 & 26 & 22.0 & \\
\hline Professional/graduate school experience & 6 & 15.4 & 27 & 22.9 & \\
\hline Age (mean, SD) & 53.3 & 11.6 & 57.6 & 10.0 & 0.0247 \\
\hline
\end{tabular}

$\star$ Percentages are calculated from total responses. If totals do not equal 158 , this reflects missing values.

†Wilcoxon rank sum test for stage at diagnosis and education (ordinal variables); Chi-square test for categorical variables; two-sample $t$-test for age (numerical variable, normally distributed).

addressing information-seeking and information use, as well as demographic and quality-of-life questions adapted from validated instruments. ${ }^{48-56}$ Subjects were from the Midwest $(n=118)$ and Northeast $(n=40)$ regions of the USA. The sample included both Latina $(n=40)$ and non-Latina $(n=118)$ women.

\section{Recruitment}

Participants were recruited through clinics, breast-cancer support groups, 
flyers, and newsletter announcements. The survey was administered to eligible women (age 18 or older, diagnosed with breast cancer) after obtaining informed consent. The research was approved by the University of Missouri-Columbia and University of Medicine and Dentistry of New Jersey Institutional Review Boards (see Appendix for Patient Health Communication and Information Survey questionnaire).

\section{Data analysis}

Frequency distributions were calculated for each categorical variable. Means and standard deviations were calculated for each quantitative variable. To compare Latina with non-Latina respondents, Chi-square tests were performed for qualitative variables; the two-sample $t$-test was performed for quantitative variables when the data were normally distributed and the Wilcoxon rank sum test was performed when the data departed from normality (Table 1). To investigate patterns of use of information sources, percentages were calculated for each information source, and for each of Longo's model's five stages of use (Table 2).

To further investigate active information-seeking behaviour, the percentage of respondents who reported they were aware of the information sources and actively tried to access them was calculated $(n=156)$. To determine if there was an association between information-seeking behaviour and ethnic background, this percentage was calculated by ethnicity, and then the Chisquared test was performed to determine whether active information-seeking behaviour is independent of ethnicity (Table 3).

The percentage of respondents was calculated who reported they were aware of information sources, actively tried to access them, and also received information from sources they did not actively seek (passive receipt of information) $(n=118)$. The Chi-squared test was used to determine if passive informationreceipt was independent of ethnicity (Table 4).

The percentage of respondents for each stage of information use was calculated for three populations relative to their information-seeking behaviour (Table 5).

To examine potential factors that predict information-seeking behaviour, three new variables, which represent the behaviour characteristics of informationseeking, were created as dependent variables for the predicting model. The three new dependent variables were 'use of website' (whether patients used any website to seek information), 'only source of information was doctors or nurses' and 'both active seekers and passive receivers of information' (whether patients both actively sought and passively received information). All demographic characteristic variables, including age, cancer stage, treatment phase, ethnic background, marital status, language and educational level, were considered as potential predictors. As the dependent variables were dichotomous, logistic regression models were used to determine variables associated with the three dependent variables. Initially all potential predictors were included in the models and stepwise selection procedures were used to identify a set of predictors. The final sets of predictors were selected for each model.

\section{RESULTS}

Demographic characteristics of study subjects are shown in Table 1. Summaries of subjects' responses to questions regarding stages of awareness and use of various 


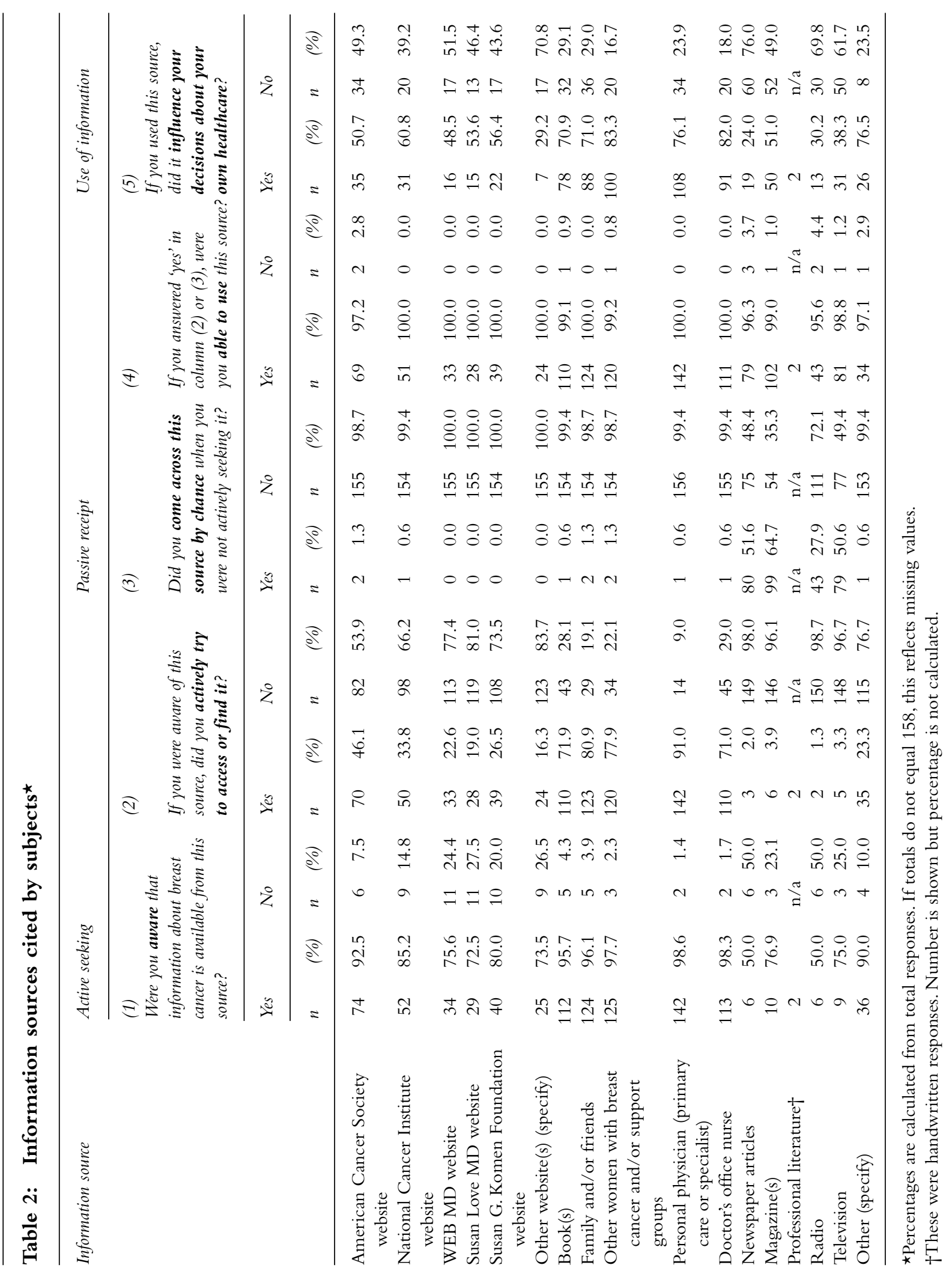


Table 3: Active information-seeking behaviour: subjects who reported they were aware of information sources and actively tried to access or find them, by information source

\begin{tabular}{|c|c|c|c|c|c|c|c|c|c|}
\hline \multirow[b]{3}{*}{ Information source } & \multicolumn{3}{|c|}{ Latina $(n=38)$} & \multicolumn{5}{|c|}{ Non-Latina $(n=118)$} & \multirow[b]{3}{*}{$p$-value } \\
\hline & \multicolumn{2}{|l|}{ Yes } & \multirow{2}{*}{$\begin{array}{c}\text { No } \\
n\end{array}$} & \multicolumn{2}{|l|}{ Yes } & \multicolumn{3}{|l|}{ No } & \\
\hline & $n$ & $(\%)$ & & $(\%)$ & $n$ & $(\%)$ & $n$ & $(\%)$ & \\
\hline American Cancer Society website & 11 & 32.4 & 23 & 67.6 & 59 & 50.0 & 59 & 50.0 & 0.0689 \\
\hline National Cancer Institute website & 5 & 16.7 & 25 & 83.3 & 45 & 38.1 & 73 & 61.9 & 0.0264 \\
\hline WEB MD website & 1 & 3.6 & 27 & 96.4 & 32 & 27.1 & 86 & 72.9 & 0.0074 \\
\hline Susan Love MD website & 2 & 6.9 & 27 & 93.1 & 26 & 22.0 & 92 & 78.0 & 0.0629 \\
\hline Susan G. Komen Foundation website & 3 & 10.3 & 26 & 89.7 & 36 & 30.5 & 82 & 69.5 & 0.0276 \\
\hline Other websites & 4 & 13.8 & 25 & 86.2 & 20 & 16.9 & 98 & 83.1 & 0.7862 \\
\hline Mayo Clinic website $\ddagger$ & $\mathrm{n} / \mathrm{a}$ & $\mathrm{n} / \mathrm{a}$ & & & 1 & $\mathrm{n} / \mathrm{a}$ & & & \\
\hline MD Anderson website $\ddagger$ & $\mathrm{n} / \mathrm{a}$ & $\mathrm{n} / \mathrm{a}$ & & & 1 & $\mathrm{n} / \mathrm{a}$ & & & \\
\hline Medline $\neq$ & $\mathrm{n} / \mathrm{a}$ & $\mathrm{n} / \mathrm{a}$ & & & 1 & $\mathrm{n} / \mathrm{a}$ & & & \\
\hline National Library of Medicine website & $\mathrm{n} / \mathrm{a}$ & $\mathrm{n} / \mathrm{a}$ & & & 1 & $\mathrm{n} / \mathrm{a}$ & & & \\
\hline National Institutes of Health website & $\mathrm{n} / \mathrm{a}$ & $\mathrm{n} / \mathrm{a}$ & & & 2 & $\mathrm{n} / \mathrm{a}$ & & & \\
\hline Sloan Kettering website & 1 & $\mathrm{n} / \mathrm{a}$ & & & $\mathrm{n} / \mathrm{a}$ & $\mathrm{n} / \mathrm{a}$ & & & \\
\hline Books & 21 & 60.0 & 14 & 40.0 & 89 & 75.4 & 29 & 24.6 & 0.0746 \\
\hline Family and/or friends & 22 & 64.7 & 12 & 35.3 & 101 & 85.6 & 17 & 14.4 & 0.0063 \\
\hline $\begin{array}{l}\text { Other women with breast cancer and/or } \\
\text { support groups }\end{array}$ & 21 & 58.3 & 15 & 41.7 & 99 & 83.9 & 19 & 16.1 & 0.0012 \\
\hline Personal physician & 35 & 92.1 & 3 & 7.9 & 107 & 90.7 & 11 & 9.3 & 1.0000 \\
\hline Doctor's office nurse & 25 & 67.6 & 12 & 32.4 & 85 & 72.0 & 33 & 28.0 & 0.6015 \\
\hline Newspaper articles & 3 & 8.8 & 31 & 91.2 & 0 & 0.0 & 118 & 100.0 & 0.0104 \\
\hline Magazines & 5 & 13.9 & 31 & 86.1 & 1 & 0.9 & 115 & 99.1 & 0.0028 \\
\hline Professional literature ${ }^{\S}$ & $\mathrm{n} / \mathrm{a}$ & $\mathrm{n} / \mathrm{a}$ & & & 2 & $\mathrm{n} / \mathrm{a}$ & & & \\
\hline Radio & 2 & 5.9 & 32 & 94.1 & 0 & 0.0 & 118 & 100.0 & 0.0489 \\
\hline Television & 5 & 14.3 & 30 & 85.7 & 0 & 0.0 & 118 & 100.0 & $<0.0001$ \\
\hline Other & 6 & 18.7 & 26 & 81.3 & 29 & 24.6 & 89 & 75.4 & 0.4895 \\
\hline
\end{tabular}

$\star$ Percentages are calculated from total responses. If totals do not equal 156, this reflects missing values.

†Chi-squared test.

¥Selected handwritten responses specifying 'other websites.' Number is shown but percentage is not calculated.

\$Handwritten responses. Number is shown but percentage is not calculated. Two of the 158 study subjects indicated they were not aware of any information sources, therefore only 156 subjects could be further classified by type of information seeking and stage of information use.

information sources are in Table 2. Note that the model assumes that awareness precedes active seeking of information, and that active seeking and/or passive receipt precede use of the source and use of the information to make healthcare decisions.

\section{Interpersonal sources}

Results indicate interpersonal communication, especially with doctors and other health professionals, is the primary information source. Nearly all patients (99 per cent) indicated awareness of their physicians as information sources and the vast majority sought information from their physicians (91 per cent); these individuals all indicated they were able to use it, and most (76 per cent) used it in making healthcare decisions. Doctor's office nurses were a very important source of information, with 98 per cent of 
Table 4: Active information-seeking behaviour and passive receipt of information: subjects who reported they were aware of information sources, actively tried to access or find them, and also received information from sources they did not actively seek, by information source*

\begin{tabular}{|c|c|c|c|c|c|c|c|c|c|}
\hline \multirow[b]{3}{*}{ Information source } & \multicolumn{3}{|c|}{ Latina $(n=38)$} & \multicolumn{3}{|c|}{ Non-Latina $(n=118)$} & \multirow[b]{3}{*}{$n$} & \multirow[b]{3}{*}{$(\%)$} & \multirow[b]{3}{*}{$p$-value ${ }^{\dagger}$} \\
\hline & Yes & & No & Yes & & No & & & \\
\hline & $n$ & $(\%)$ & $n$ & $(\%)$ & $n$ & $(\%)$ & & & \\
\hline American Cancer Society website & 8 & 33.3 & 16 & 66.7 & 51 & 55.4 & 41 & 44.6 & 0.0538 \\
\hline National Cancer Institute website & 3 & 15.0 & 17 & 85.0 & 41 & 44.6 & 51 & 55.4 & 0.0141 \\
\hline WEB MD website & 1 & 5.3 & 18 & 94.7 & 28 & 30.4 & 64 & 69.6 & 0.0225 \\
\hline Susan Love MD website & 2 & 10.0 & 18 & 90.0 & 23 & 25.0 & 69 & 75.0 & 0.2348 \\
\hline Susan G. Komen Foundation website & 3 & 15.0 & 17 & 85.0 & 33 & 35.9 & 59 & 64.1 & 0.0701 \\
\hline Other websites & 2 & 10.0 & 18 & 90.0 & 18 & 19.6 & 74 & 80.4 & 0.5196 \\
\hline Mayo Clinic website $\ddagger$ & $\mathrm{n} / \mathrm{a}$ & $\mathrm{n} / \mathrm{a}$ & & & 1 & $\mathrm{n} / \mathrm{a}$ & & & \\
\hline MD Anderson website $\ddagger$ & $\mathrm{n} / \mathrm{a}$ & $\mathrm{n} / \mathrm{a}$ & & & 1 & $\mathrm{n} / \mathrm{a}$ & & & \\
\hline Medline $\ddagger$ & $\mathrm{n} / \mathrm{a}$ & $\mathrm{n} / \mathrm{a}$ & & & 1 & $\mathrm{n} / \mathrm{a}$ & & & \\
\hline National Library of Medicine website $\ddagger$ & $\mathrm{n} / \mathrm{a}$ & $\mathrm{n} / \mathrm{a}$ & & & 1 & $\mathrm{n} / \mathrm{a}$ & & & \\
\hline National Institutes of Health website $\neq$ & $\mathrm{n} / \mathrm{a}$ & $\mathrm{n} / \mathrm{a}$ & & & 2 & $\mathrm{n} / \mathrm{a}$ & & & \\
\hline Sloan Kettering website $\neq$ & $\mathrm{n} / \mathrm{a}$ & $\mathrm{n} / \mathrm{a}$ & & & $\mathrm{n} / \mathrm{a}$ & $\mathrm{n} / \mathrm{a}$ & & & \\
\hline Books & 18 & 75.0 & 6 & 25.0 & 82 & 89.1 & 10 & 10.9 & 0.0960 \\
\hline Family and/or friends & 18 & 75.0 & 6 & 25.0 & 85 & 92.4 & 7 & 7.6 & 0.0266 \\
\hline $\begin{array}{l}\text { Other women with breast cancer and/or } \\
\text { support groups }\end{array}$ & 16 & 66.7 & 8 & 33.3 & 85 & 92.4 & 7 & 7.6 & 0.0027 \\
\hline Personal physician & 24 & 92.3 & 2 & 7.7 & 86 & 93.5 & 6 & 6.5 & 1.0000 \\
\hline Doctor's office nurse & 16 & 64.0 & 9 & 36.0 & 75 & 81.5 & 17 & 18.5 & 0.0617 \\
\hline Newspaper articles & 1 & 4.5 & 21 & 95.5 & 0 & 0.0 & 92 & 100.0 & 0.1930 \\
\hline Magazines & 3 & 12.5 & 21 & 87.5 & 1 & 1.1 & 91 & 98.9 & 0.0275 \\
\hline Professional literature $\int$ & $\mathrm{n} / \mathrm{a}$ & $\mathrm{n} / \mathrm{a}$ & & & 2 & $\mathrm{n} / \mathrm{a}$ & & & \\
\hline Radio & 0 & 0.0 & 22 & 100.0 & 0 & 0.0 & 92 & 100.0 & $\mathrm{n} / \mathrm{a}$ \\
\hline Television & 3 & 13.0 & 20 & 87.0 & 0 & 0.0 & 92 & 100.0 & 0.0072 \\
\hline Other & 6 & 26.1 & 17 & 73.9 & 25 & 27.2 & 67 & 72.8 & 0.1628 \\
\hline
\end{tabular}

$\star$ Percentages are calculated from total responses. If totals do not equal 118, this reflects missing values.

$\dagger$ Chi-squared test.

¥Selected handwritten responses specifying 'other websites.' Number is shown but percentage is not calculated.

\$Handwritten responses. Number is shown but percentage is not calculated. Two of the 158 study subjects indicated they were not aware of any information sources, therefore only 156 subjects could be further classified by type of information seeking and stage of information use. Of the 156, who were aware and reported active seeking, 118 also reported passive receipt of information; responses from those 118 subjects are shown in this table.

respondents aware and 71 per cent actively seeking information; all of those who received information were able to use it, and 82 per cent used it to make healthcare decisions.

Other breast-cancer patients and/or support groups ranked almost evenly with medical professionals as sources of informa- tion (98 per cent aware, 78 per cent actively seeking information). Almost all respondents who sought or received information from other patients or support groups were able to use it, and 83 per cent used it to make healthcare decisions.

Family members and/or friends also played a prominent role, with 96 per cent 
Table 5: Stages of information use by subjects with breast cancer ${ }^{\star}$

\begin{tabular}{|c|c|c|c|c|c|}
\hline \multirow[b]{2}{*}{ Population and stage } & \multicolumn{2}{|c|}{ Latina } & \multicolumn{2}{|c|}{ Non-Latina } & \multirow[b]{2}{*}{ p-value } \\
\hline & $n$ & $(\%)$ & $n$ & $(\%)$ & \\
\hline \multicolumn{6}{|l|}{ Active information seekers $(n=156)$} \\
\hline 1. Aware & 40 & 100.0 & 116 & 100.0 & \multirow{7}{*}{0.0166} \\
\hline 2. Aware, but does not attempt to access & 0 & 0.0 & 0 & 0.0 & \\
\hline 3. Aware, attempts to access & 40 & 100.0 & 116 & 100.0 & \\
\hline 4. Accesses, but is not able to use & 0 & 0.0 & 0 & 0.0 & \\
\hline 5. Accesses, is able to use & 40 & 100.0 & 116 & 100.0 & \\
\hline $\begin{array}{l}\text { 6. Uses, but does not use to make healthcare } \\
\text { decisions }\end{array}$ & 7 & 18.4 & 6 & 5.1 & \\
\hline 7. Uses to make healthcare decisions & 31 & 81.6 & 112 & 94.92 & \\
\hline \multicolumn{6}{|c|}{ Active seekers and additional passive receipt of information $(n=118)$} \\
\hline 1. Does not passively receive information & 36 & 100.0 & 92 & 100.0 & \\
\hline 2. Passively receives information & 0 & 0.0 & 0 & 0.0 & \multirow{5}{*}{0.2104} \\
\hline 3. Receives information, but does not use & 36 & 100.0 & 92 & 100.0 & \\
\hline 4. Receives information and uses & 0 & 0.0 & 0 & 0.0 & \\
\hline $\begin{array}{l}\text { 5. Uses, but does not use to make healthcare } \\
\text { decisions }\end{array}$ & 2 & 7.7 & 2 & 2.8 & \\
\hline 6. Uses to make healthcare decisions & 24 & 92.3 & 90 & 97.8 & \\
\hline \multicolumn{6}{|c|}{ Source of information was only physician or nurse $(n=9)$} \\
\hline 1. Information provided & 4 & 100.0 & 5 & 100.0 & \multirow{4}{*}{0.5238} \\
\hline 2. Information provided but not used & 0 & 0.0 & 0 & 0.0 & \\
\hline $\begin{array}{l}\text { 3. Information provided but not used to make } \\
\text { healthcare decisions }\end{array}$ & 2 & 50.0 & 1 & 20.0 & \\
\hline 4. Uses to make healthcare decisions & 2 & 50.0 & 4 & 80.0 & \\
\hline
\end{tabular}

$\star$ Because subjects identified a variety of different information sources, as well as active information seeking, and active and passive, there are no mutually exclusive categories. No subjects reported only passive information receipt.

†Two of the 158 study subjects indicated they were not aware of any information sources, therefore only 156 subjects could be further classified by type of information seeking and stage of information use.

of respondents aware of these people as information sources, and 81 per cent stating they actively sought information. All who sought or received information from family and friends indicated they were able to use it, and 71 per cent used it to make healthcare decisions.

\section{Website use}

Five major websites were among sources for which subjects were asked to indicate their awareness and use; they were also asked about use of other websites and asked to specify which sites they had used. The majority of respondents were aware of the five major sites, and a large proportion actively tried to access one or more of these sites. The American Cancer Society (ACS) and National Cancer Institute (NCI) websites ranked first and second, respectively, on both awareness and use, with 93 per cent and 85 per cent, respectively, of respondents indicating they were aware of these sites; 46 per cent and 34 per cent, respectively, reported they actively sought information from these sites. The next most frequently cited websites were the Susan G. Komen 
Foundation (80 per cent aware, 27 per cent sought to access); WEB MD (76 per cent aware, 23 per cent sought to access), and Susan Love, MD, website (73 per cent aware, 19 per cent sought to access). About half of those who obtained information from these five websites indicated they used it in making healthcare decisions, with the NCI site being the highest ranked for decision-making usefulness (61 per cent).

A variety of 'other' websites were cited, with 16 per cent of respondents indicating they actively sought information from one or more of these. Examples include government sites (eg National Library of Medicine, National Institutes of Health), universities and medical centres, organisations (eg Imaginis, friendsinneed.com, Y$\mathrm{Me}$ ); search sites (eg Medline, Association of Cancer Online Resources) and alternative medicine sites.

\section{Information from books}

A vast majority of respondents (96 per cent) were aware of information in books; a higher percentage than those aware of the websites, and 72 per cent actively tried to access this information. Most importantly, an overwhelming majority (99 per cent) reported using this information, with 71 per cent using it to make healthcare decisions.

\section{Traditional mass media}

Among traditional mass media, magazines were most frequently cited in terms of awareness (77 per cent), and respondents indicated magazines were both actively sought and passively received. Interestingly, nearly all respondents who sought or received information from magazines reported they were able to use it (99 per cent), with 51 per cent indicating they used it to make healthcare decisions. Some respondents also indicated that they were aware of and used medical profes- sional journals, but this was the exception rather than the rule.

Some respondents reported television (75 per cent), newspapers (50 per cent), and radio (50 per cent) as sources of information, but fewer used it in making healthcare decisions (38 per cent, 24 per cent, and 30 per cent, respectively). Information from these sources was more typically passively received through leisure viewing/reading/listening or 'channel surfing', rather than actively sought.

\section{Influence of race/ethnicity}

Tables 3 and 4 display results of comparisons of information-use patterns by race/ethnicity. Data were included for all study subjects (Table 3 ) who actively sought information $(n=156)$ from one or more source(s). In Table 4, only those subjects who both actively sought and passively received information $(n=118)$ are reported. In both the 'active' and 'active and passive' groups, non-Latina women were more likely to seek information from family and/or friends $(p=0.0063$ for 'active', $p=0.0266$ for 'active and passive'), and from others with breast cancer and/or support groups $(p=0.0012$ for 'active', $p=0.0027$ for 'active and passive').

Among the larger group of active information seekers (Table 3), NonLatina women were more likely than Latina women to actively seek information from websites; this difference was statistically significant for the NCI $(p=0.0264)$, WEB MD $(p=0.0074)$, and Susan Komen $(p=0.0276)$ websites. A similar pattern was observed for the subset of women who both actively sought and passively received information, although the difference was significant for only the NCI $(p=0.0141)$ and WEB MD $(p=0.0225)$ websites.

Table 5 stages respondents according to 
model categories. Of the 156 patients who could be classified as active seekers of information, all stated that they were aware of one or more information source(s), and were able to access and use this information. Nearly all (92 per cent) indicated that they used one or more of these information source(s) to make healthcare decisions. Of the 118 patients classified as both active seekers and passive receivers of information, all indicated they were able to use the information they received, and 97 per cent used it to make healthcare decisions. Among active information seekers $(n=156)$, non-Latinas were more likely to use information to make decisions $(p=0.0166)$. For respondents who both actively and passively received information, there were no statistically significant differences between Latinas and non-Latinas. No respondents reported only passive receipt of information.

Nine patients (see Table 5) reported receiving information only from their physician and/or nurse; five of those received information from both their doctor and nurse. While these patients were initially classified as 'active information seekers' based on their taking the initiative to seek physician consultation, in reality there is insufficient information to definitively classify them into active or passive categories. It is possible that while these patients sought care, they did not actively seek any information other than what was offered by the doctor or nurse in the clinical encounter.

Logistic regression results (not shown in tables) indicated that English-speaking or bilingual patients are more likely to use websites than those who speak Spanish only $(\mathrm{OR}=4.17 ; \quad \mathrm{CI}=1.34$ 13.04, $p=0.0139)$. Younger women are more likely to use websites $(\mathrm{OR}=1.83$; $\mathrm{CI}=1.28-2.62, p=0.0009)$, and older women are more likely to rely on their doctor or nurse as their only source of information about breast cancer $\quad(\mathrm{OR}=2.56 ; \quad \mathrm{CI}=1.40-4.69$; $p=0.0023)$. English-speaking or bilingual patients are more likely than those who speak Spanish only to receive information both actively and passively $(\mathrm{OR}=3.16$; $\mathrm{CI}=1.24-8.05 ; p=0.0162)$.

\section{DISCUSSION}

This study is one of the first to assess the combination of both passive and active information receipt, and explicitly follows the revised Longo conceptual model that takes into account health literacy and cross-cultural communication concerns; further it evaluates the influence and importance of the internet as a cancer information source in the 21st century. While most women were found to be active information seekers, many were also passive receivers. While the internet was an important source of information for patients, physicians remain the primary source of information. This pilot study provides insight into patients' use of health information to make more informed health decisions, and it supports Little and colleagues' finding that patients strongly prefer a patient-centred approach. ${ }^{57}$ It is likely that dissemination of these findings to oncologists and others who treat these patients may change clinical practice and/or thinking about what information is provided or recommended to patients.

The implications of this study may perhaps best be discussed in light of the National Cancer Institute's 'Making Health Communication Programs Work ${ }^{58}$ and the four stages it proposes.

\section{Planning and strategy development}

Effective communication programmes must be based on an understanding of the needs as well as perceptions of the 
intended audience. Despite the widelyheld belief regarding the internet as a major source of information, interpersonal communication (doctors, nurses, other patients, family, and friends) was far more often cited as a source of information than either the internet or traditional print and broadcast media. The data showed websites to be an important source of breast-cancer information, but - contrary to perceptions in some of the literature $e^{59-63}$ - the internet has not replaced, but likely supplements, traditional sources of information such as doctor and nurse, family and friends, books and other printed resources, and broadcast media. Future communication programmes must take into account the strategic role the healthcare provider still plays despite the explosion of the internet and other communication avenues.

\section{Developing and pretesting concepts, messages and materials}

This study, as others, indicates that patients may also lack the health literacy necessary to understand and use medical information. ${ }^{64}$ Differing levels of literacy span across racial and ethnic groups, with language barriers playing a major role. Findings indicate that higher internet use is associated with younger age and with English-speaking and bilingual (English/Spanish) patients, compared to Spanish-speaking only. Thus, effective communication programmes aimed at these target populations must develop relevant and meaningful messages, and plan and pre-test these with the target population in mind. For example, this study found that magazines were cited frequently as a passively received information source. It is important for healthcare providers to develop communication strategies which recognise that during the course of daily activities such as leisure reading, patients may come across pertinent medical information that may influence their healthcare decisions. This is especially true for breast cancer, given the current level of proactive awareness efforts in many popular magazines (eg Redbook, Self, Good Housekeeping). This step is critical in identifying vital communication avenues that health professionals may overlook or neglect, yet patients may greatly rely upon.

\section{Implementing the programme}

While the findings do not directly address this fourth step in the NCI strategy, they do emphasise the vital role of keeping current with and understanding patient perspectives in the aggregate as well as subpopulations of patients; this is key to the success of any communication strategy. This is seen in the observed differences between the Latina and nonLatina populations where 'one size does not fit all'.

\section{Assessing effectiveness and making refinements}

This is the fourth step in the NCI model and is best reflected in the necessity for the present investigation to revise its conceptual model from that initially proposed in Health Communications to explicitly take into account health literacy as well as related cross-cultural communication issues. For example, as the overall design of this study examined differences between Latinas and non-Latinas it was possible to explicitly examine and identify important cross-cultural differences; these differences would have been lost had the initial study to examine the information needs of women with breast cancer not been refined to the more specific approach taken in the present study.

\section{Limitations}

This study is based on self-reported data and may be affected by information recall 
bias. Future studies should include more extensive follow-up questions, supplemented by in-depth interviews and/or direct observation of physician-patient encounters, to further explore the degree to which information-seeking in doctor/patient, nurse/patient encounters is active versus passive. As some subject recruitment was done through breastcancer support groups, some results may be skewed regarding information receipt and use from friends and support groups. More work is needed to determine whether patients who indicated they were not able to use given sources of information did so because of issues related to use of the medium (eg lack of access to a computer), versus the information itself (eg doubts about credibility, information not applicable to patient's situation). Further work with larger samples in the USA and international sites, as well as further survey instrument refinement will also help determine the generalisability of these pilot findings.

\section{AcKNowledgments}

Funding was provided through a research development grant from the Department of Family and Community Medicine at University of Missouri-Columbia. The authors express appreciation to John Hewett, $\mathrm{PhD}$, for statistical consultation on this project, and to Shari Schubert, BA, for assistance in all aspects of this study including administrative coordination of the study and preparation of the manuscript for publication.

\section{References}

(1) Shibuya, K., Mathers, C. D., Boschi-Pinto, C., Lopez, A. D. and Murray, C. J. (2002) 'Global and regional estimates of cancer mortality and incidence by site: II. Results for the global burden of disease 2000', BMC Cancer, Vol. 2, pp. 37.

(2) American Cancer Society (2005) 'Breast Cancer Facts \& Figures 2005-2006', American Cancer Society, Atlanta, GA.

(3) Centers for Disease Control and Prevention (2006) 'Cancer: selected US national research findings', available at: www.cdc.gov/women /natstat/cancer.htm\#breast (accessed 30 September, 2006).

(4) Ries, LAG, Harkins, D., Krapcho. M., Mariotto, A. et al. 'SEER cancer statistics review, 1975-2003’ (2006) available at: http://seer.cancer.gov/csr/ 1975_2003/ (accessed 30 September, 2006).

(5) Radina, M. E., Longo, D. R. and Armer, J. M. (2005) 'Latinas and breast cancer in the midwest: factors influencing survivorship', International Journal of Global Health and Health Disparities, Vol. 3, No. 2, pp. 40-60.

(6) Owens, B. and Dirksen, S. R. (2004) 'Review and critique of the literature of complementary and alternative therapy use among Hispanic/Latino women with breast cancer', Clinical Journal of Oncology Nursing, Vol. 8, No. 2, pp. 151-156.

(7) Clegg, L. X., Li, F. P., Hankey, B. F., Chu, K. and Edwards, B. K. (2002) 'Cancer survival among US whites and minorities: a SEER (Surveillance, Epidemiology, and End Results) Program population-based study', Archives of Internal Medicine, Vol. 162, No. 17, pp. 1985-1993.

(8) Jemal, A., Clegg, L. X., Ward, E., Ries, L. A., Wu, X., Jamison, P. M., et al. (2004) 'Annual report to the nation on the status of cancer, 1975-2001, with a special feature regarding survival', Cancer, Vol. 101, No. 1, pp. 3-27.

(9) Radina et al., ref. 5 above.

(10) Howe, H. L., Xiaocheng, W., Ries, L. A. G., Cokkinides, V., Ahmed, F., Jemal, A., et al. (2006) 'Annual report to the nation on the status of cancer, 
1975-2003, featuring cancer among U.S. Hispanic/Latino populations', Cancer, Vol. 107, No. 8, pp. 1711-1742.

(11) Li, C. I. (2005) 'Racial and ethnic disparities in breast cancer stage, treatment, and survival in the United States', Ethnicity \& Disease, Vol. 15, No. 2, Suppl. 2, pp. S5-S9.

(12) Helft, P. R. (2004) 'Breast cancer in the information age: a review of recent developments', Breast Disease, Vol. 21, No. 1, pp. 41-46.

(13) Ibid.

(14) Berland, G. K., Elliott, M. N., Morales, L. S., Algazy, J. I., Kravitz, R. L., Broder, M. S., et al. (2001) 'Health information on the internet: accessibility, quality, and readability in English and Spanish', Journal of the American Medical Association, Vol. 285, No. 20, pp. 2612-2621.

(15) Counts, L. (2005) 'Can internet medical information be trusted?', National Network, Vol. 30, No. 1, p. 6.

(16) Friedman, D. B., Hoffman-Goetz, L. and Arocha, J. F. (2004) 'Readability of cancer information on the internet', Journal of Cancer Education, Vol. 19, No. 2, pp. 117-122.

(17) Seidman, J. J., Steinwachs, D. and Rubin, H. R. (2003) 'Conceptual framework for a new tool for evaluating the quality of diabetes consumer-information web sites', Journal of Medical Internet Research, Vol. 5, No. 4, p. e29.

(18) Meric, F., Bernstam, E. V., Mirza, N. Q., Hunt, K. K., Ames, F. C., Ross, M. I., et al. (2002) 'Breast cancer on the world wide web: cross sectional survey of quality of information and popularity of websites', British Medical Journal (Clinical Research Edn.), Vol. 324, No. 7337, pp. 577-581.

(19) Friedman et al., ref. 16 above.

(20) Weissenberger, C., Jonassen, S., Beranek-Chiu, J., Neumann, M., Muller, D., Bartelt, S., et al. (2004) 'Breast cancer: patient information needs reflected in English and German web sites', British Journal of Cancer, Vol. 91, No. 8, pp. 1482-1487.

(21) Berland et al., ref. 14 above.

(22) Ibid.

(23) Gustafson, D. H., McTavish, F. M., Stengle, W., Ballard, D., Jones, E., Julesberg, K., et al. (2005) 'Reducing the digital divide for low-income women with breast cancer: a feasibility study of a population-based intervention', Journal of Health Communication, Vol. 10, Suppl. 1, pp. 173-193.

(24) Hibbard, J. H., Greenlick, M., Jimison, H., Kunkel, L. and Tusler, M. (1999) 'Prevalence and predictors of the use of self-care resources', Evaluation \& the Health Professions, Vol. 22, No. 1, pp. 107-122.

(25) Baergen-Fladager, S. (2001) 'Health and literacy: What is the connection?' ERIC, Resources in Education.

(26) Birru, M. S., Monaco, V. M., Charles, L., Drew, H., Njie, V., Bierria, T., et al. (2004) 'Internet usage by low-literacy adults seeking health information: an observational analysis', Journal of Medical Internet Research, Vol. 6, No. 3, pp. e25.

(27) Kobylarz, F. A., Pomidor, A. and Heath, J. M. (2006) 'SPEAK. A mnemonic tool for addressing health literacy concerns in geriatric clinical encounters', Geriatrics, Vol. 61, No. 7, pp. 20-26.

(28) Marcus, E. N. (2006) 'The silent epidemic - the health effects of illiteracy', New England Journal of Medicine, Vol. 355, No. 4, pp. 339-341.

(29) Arah, O. A., ten Asbroek, A. H., Delnoij, D. M., de Koning, J. S., Stam, P. J., Poll, A. H., et al. (2006) 'Psychometric properties of the Dutch version of the Hospital-level Consumer Assessment of Health Plans Survey instrument', Health Service Research, Vol. 41, No. 1, pp. 284-301.

(30) Carlsson, M. (2000) 'Cancer patients seeking information from sources outside the healthcare system', 
Supportive Care in Cancer, Vol. 8, No. 6, pp. 453-457.

(31) Dutta-Bergman, M. J. (2004) 'Primary sources of health information: comparisons in the domain of health attitudes, health cognitions, and health behaviours', Health Communication, Vol. 16, No. 3, pp. 273-288.

(32) Shim, M., Kelly, B. and Hornik, R. (2006) 'Cancer information scanning and seeking behaviour is associated with knowledge, lifestyle choices, and screening', Journal of Health Communication, Vol. 11, Suppl. 1, pp. 157-172.

(33) Ibid.

(34) Ibid.

(35) Carlsson et al., ref. 30 above.

(36) de Haes, H. (2006) 'Dilemmas in patient centeredness and shared decision making: a case for vulnerability', Patient Education \& Counseling, Vol. 62, No. 3, pp. 291-298.

(37) Neuberger, J. (2000) 'The educated patient: new challenges for the medical profession', Journal of Internal Medicine, Vol. 247, No. 1, pp. 6-10.

(38) Drain, M. (2003) 'Consumerism and patient satisfaction. Foreword', Journal of Ambulatory Care Management, Vol. 26, No. 2, pp. 96-99.

(39) Maly, R. C., Umezawa, Y., Leake, B. and Silliman, R. A. (2004)

'Determinants of participation in treatment decision-making by older breast cancer patients', Breast Cancer Research \& Treatment, Vol. 85, No. 3, pp. 201-209.

(40) Longo, D. R. (2005) 'Understanding health information, communication, and information seeking of patients and consumers: a comprehensive and integrated model', Health Expectations, Vol. 8, pp. 189-194.

(41) Irwin, R. S. and Richardson, N. D. (2006) 'Patient-focused care: using the right tools', Chest, Vol. 130, No. 1 (Suppl.), pp. 73S-82S.

(42) Little, P., Everitt, H., Williamson, I., Warner, G., Moore, M., Gould, C., et al. (2001) 'Observational study of effect of patient centredness and positive approach on outcomes of general practice consultations', British Medical Journal (Clinical Research Edn.), Vol. 323, No. 7318, pp. 908-911.

(43) Stewart, M., Brown, J. B., Donner, A., McWhinney, I. R., Oates, J., Weston, W. W. and Jordan, J. (2000) 'The impact of patient-centered care on outcomes', Journal of Family Practice, Vol. 49, No. 9, pp. 796-804.

(44) Talosig-Garcia, M. and Davis, S. (2005) 'Information-seeking behaviour of minority breast cancer patients: an exploratory study', Journal of Health Communication, Vol. 10, Suppl. 1, pp. 53-64.

(45) Zarbock, S. F. (2001) 'Meeting the information needs of patients with metastatic breast cancer', Home Care Provider, Vol. 6, No. 1, pp. 37-40.

(46) Talosig-Garcia et al., ref. 44 above.

(47) Treiman, K. and Squiers, L. (2005) 'The CIS research agenda: overview of relevant research', National Cancer Institute, Cancer Information Service, Office of Communications, Bethesda, MD.

(48) American Cancer Society. (1997) 'National quality of life survey', American Cancer Society, Behavioural Research Center, Atlanta, GA.

(49) Baker, F., Denniston, M., Zabora, J., Polland, A. and Dudley, W. N. (2002) 'A POMS short form for cancer patients: psychometric and structural evaluation', Psycho-Oncology, Vol. 11, No. 4, pp. 273-281.

(50) Shacham, S. (1983) 'A shortened version of the Profile of Mood States', Journal of Personality Assessment, Vol. 47, No. 3, pp. 305-306.

(51) Brady, M. J., Cella, D. F., Mo, F., Bonomi, A. E., Tulsky, D. S., Lloyd, S. R., et al. (1997) 'Reliability and validity of the Functional Assessment of Cancer Therapy-Breast quality-of-life instrument', Journal of Clinical Oncology, Vol. 15, No. 3, pp. 974-986. 
(52) Cella, D. F. (2003) 'FACT-B (Version 4)', available at: www.facit.org (accessed 30 July, 2003).

(53) Baker, F., Curbow, B. and Wingard, J. R. (1992) 'Development of the satisfaction with life domains scale for cancer', Journal of Psychosocial Oncology, Vol. 10, No. 3, pp. 75-90.

(54) Watson, M., Greer, S., Young, J., Inayat, Q., Burgess, C. and Robertson, B. (1988) 'Mental adjustment to cancer (MAC) scale', CRC Psychological Medicine Group, The Royal Marsden Hospital, Sutton.

(55) Zimet, G. D., Dahlem, N. W., Zimet, S. G. and Farley, G. K. (1988) 'The multidimensional scale of perceived social support', Journal of Personality Assessment, Vol. 52, No. 1, pp. 30-41.

(56) Ferreira-Pinto, J. B. (1999) 'Reliability and validity of the 5 -Item Language-Based Latino Acculturation Scale', Free Inquiry in Creative Sociology, Vol. 27, No. 2, pp. 93-99.

(57) Little, P., Everitt, H., Williamson, I., Warner, G., Moore, M., Gould, C., et al. (2001) 'Preferences of patients for patient centred approach to consultation in primary care: observational study', British Medical Journal (Clinical Research Edn.), Vol. 322, No. 7284, pp. $468-472$.
(58) National Cancer Institute (US), Office of Cancer Communications (2002) 'Making Health Communication Programs Work: A Planner's Guide'. Department of Health and Human Services, Public Health Service, National Institutes of Health Office of Cancer Communications, National Cancer Institute, Bethesda, MD.

(59) Helft, ref. 12 above.

(60) Weissenberger et al., ref. 20 above.

(61) Teo, N. B., Paton, P. and Kettlewell, S. (2005) 'Use of an interactive web-based questionnaire to evaluate a breast cancer website', Breast, Vol. 14, No. 2, pp. 153-156.

(62) Fogel, J. (2004) 'Internet breast health information use and coping among women with breast cancer', Cyberpsychology \& Behaviour, Vol. 7, No. 1, pp. 59-63.

(63) Dolinsky, C. M., Wei, S. J., Hampshire, M. K. and Metz, J. M. (2006) 'Breast cancer patients' attitudes toward clinical trials in the radiation oncology clinic versus those searching for trial information on the internet', Breast Journal, Vol. 12, No. 4, pp. 324-330.

(64) Nielsen-Bohlman, L., Panzer, A. M., Kindig, D. A., Institute of Medicine. (2004) 'Health literacy: a prescription to end confusion', National Academies Press, Washington, DC. 


\section{APPENDIX: PATIENT HEALTH COMMUNICATION AND INFORMATION SURVEY}

Participant ID number

1. How long has it been since you were first diagnosed with breast cancer?
Less than 1 year

1 year or more, but less than 2 years

2 years or more, but less than 3 years

- 3 years or more, but less than 4 years

- 4 years or more, but less than 5 years

— 5 years or more

2. To the best of your knowledge, what was the stage of your breast cancer at diagnosis?

Stage 0: Also known as ductal carcinoma in situ or lobular carcinoma in situ, which means the cancer cells are located within a duct and have not invaded the surrounding fatty breast tissue or that the abnormal cells grow within the lobules or milk-producing glands, but they do not penetrate through the wall of these lobules.

_ Stage I: The tumor is $2 \mathrm{~cm}$ or less in diameter and has not spread to lymph nodes or anywhere else.

Stage II: The tumor is between $2 \mathrm{~cm}$ and $5 \mathrm{~cm}$ in diameter or it has spread to 1-3 underarm lymph nodes on the same side as the breast cancer. Both of these can be present also. The tumor may also be larger than $5 \mathrm{~cm}$ but has not spread to lymph nodes.

_ Stage III: The tumor is either smaller than $5 \mathrm{~cm}$ in diameter and has spread to 4-9 underarm lymph nodes, larger than $5 \mathrm{~cm}$ and has spread to 1-9 underarm nodes, the tumor has grown into the chest wall or skin and 0-9 nodes are involved, or the tumor is any size has spread to 10 or more nodes in the underarm or to lymph nodes under the clavicle (infraclavicular) or above the clavicle (supraclavicular) or to lymph nodes in the chest near the breast bone (internal mammary). Patients with stage III cancer show no signs that the cancer has spread to distant organs or bones. Inflammatory breast cancer is classified as stage III, unless it has spread to distant organs or lymph nodes that are not near the breast, in which case it would be stage IV.

Stage IV: The cancer, regardless of its size, has metastasized to distant organs such as bones or lungs or to lymph nodes not near the breast.

I I don't know.

3. To the best of your knowledge, what best describes the phase of breast cancer treatment you are in now?

Phase 2 - you have had an abnormal mammogram or breast exam, and your doctor plans to evaluate you and diagnose the problem

Phase 3 - you are currently undergoing treatment (surgery, chemotherapy, or radiation) for breast cancer

_ Phase 4 - you have completed the treatment of your breast cancer, and you are either in remission (there is no longer evidence of cancer in your body), or the breast cancer has reoccurred

_ Phase 5 - you have long-term breast cancer and may or may not be undergoing comfort care

4. At the time of your diagnosis, did you seek additional information about breast cancer, other than that provided through your doctor's office?

\section{Do you have access to a computer with internet connection? _ yes _ no}

6. Do you have access to a public library or school/university library?

$\begin{array}{cc}\text { yes }^{\text {yes }} & -{ }^{\mathrm{no}} \\ - \text { yes } & -{ }^{\mathrm{no}} \\ \text { yes }^{\mathrm{no}} & -{ }^{\mathrm{n}}\end{array}$

9. Do you read a newspaper on a regular basis?

10. Do you read popular magazines on a regular basis? 


\section{Before continuing, please read:}

The questions on the following pages will help us better understand how you and other women with breast cancer receive and use information on topics such as the symptoms, causes, diagnosis and prognosis of breast cancer; available breast cancer treatments and services; the cost and quality of health care services and providers; and the quality of the health care plan or insurance that pays for your care. We define "information" broadly, to include any information you may have received, through traditional mass media, the internet, online discussion groups, or personal interactions with health care professionals, friends, family, or other women with breast cancer. You may have intentionally sought this information (active information seeking), or you may have come across it when you were not actively seeking it, for instance, while watching television, reading a popular magazine, or visiting with a friend (passive information receipt).

11. For each source of information in the following list, please circle your answer, yes or no, to the five questions regarding your awareness and use of these sources.

\section{INFORMATION SOURCE}

American Cancer Society website

National Cancer Institute website

WEB MD website

Susan Love MD website

Susan G. Komen Foundation website

Other website(s) (specify)

\section{ACTIVE SEEKING}

(1)

Were you

aware that

information is

available from

this source?

or find it?
on

yes no yes no

yes no

yes no

yes no

yes no

yes no
(2)

If you were aware of this source, did you actively or find it?

yes no

yes no

yes no

yes no

yes no

yes no
PASSIVE
RECEIPT

(3)

Did you come across this source by

chance when you were not actively seeking it?

yes no

yes no

yes no

yes no

yes no

yes no
USE OF INFORMATION

(4)

If you answered "yes" in

column (2) or

(3), were you

able to use

this source?

yes no

yes no

yes no

yes no

yes no

yes no
(5)

If you used this source, did it influence your

decisions about your own health care? yes no yes no yes no yes no yes no yes no
Newspaper articles

Book(s)

Magazine(s)

Radio

Television

Hospital or clinic booklet(s), brochure(s) or similar information piece(s)

Family and/or friends

Other women with breast cancer and/or support groups

Personal physician (primary care or specialist)

Doctor's office nurse

Other (specify)

$\begin{array}{llllllllll}\text { yes } & \text { no } & \text { yes } & \text { no } & \text { yes } & \text { no } & \text { yes } & \text { no } & \text { yes } & \text { no } \\ \text { yes } & \text { no } & \text { yes } & \text { no } & \text { yes } & \text { no } & \text { yes } & \text { no } & \text { yes } & \text { no } \\ \text { yes } & \text { no } & \text { yes } & \text { no } & \text { yes } & \text { no } & \text { yes } & \text { no } & \text { yes } & \text { no } \\ \text { yes } & \text { no } & \text { yes } & \text { no } & \text { yes } & \text { no } & \text { yes } & \text { no } & \text { yes } & \text { no } \\ \text { yes } & \text { no } & \text { yes } & \text { no } & \text { yes } & \text { no } & \text { yes } & \text { no } & \text { yes } & \text { no } \\ \text { yes } & \text { no } & \text { yes } & \text { no } & \text { yes } & \text { no } & \text { yes } & \text { no } & \text { yes } & \text { no } \\ & & & & & & & & & \\ \text { yes no } & \text { yes } & \text { no } & \text { yes } & \text { no } & \text { yes } & \text { no } & \text { yes } & \text { no } \\ \text { yes } & \text { no } & \text { yes } & \text { no } & \text { yes } & \text { no } & \text { yes } & \text { no } & \text { yes } & \text { no } \\ \text { yes no } & \text { yes } & \text { no } & \text { yes no } & \text { yes no } & \text { yes } & \text { no } \\ \text { yes } & \text { no } & \text { yes } & \text { no } & \text { yes } & \text { no } & \text { yes } & \text { no } & \text { yes } & \text { no } \\ \text { yes } & \text { no } & \text { yes } & \text { no } & \text { yes } & \text { no } & \text { yes } & \text { no } & \text { yes } & \text { no }\end{array}$

\section{Page 204}


12. In the following list, please rate the credibility of each source that you used to find information on breast cancer. By "credible," we mean information that you (1) have the skills to access, evaluate, and use; and also (2) have found to be believable and useful in your breast cancer decision-making and self-care. Circle only one rating for each source. If you did not use a particular source of information, circle the X under "Did not use."

\section{INFORMATION SOURCE}

American Cancer Society website

National Cancer Institute website

WEB MD website

Susan Love MD website

Susan G. Komen Foundation website

Other website(s) (specify)

\begin{tabular}{cccccc} 
Did not & \multicolumn{5}{c}{ Rate the credibility of this source: } \\
\cline { 2 - 5 } use & Poor & Fair & Average & Good & Excellent \\
X & 1 & 2 & 3 & 4 & 5 \\
X & 1 & 2 & 3 & 4 & 5 \\
X & 1 & 2 & 3 & 4 & 5 \\
X & 1 & 2 & 3 & 4 & 5 \\
X & 1 & 2 & 3 & 4 & 5 \\
X & 1 & 2 & 3 & 4 & 5
\end{tabular}

Newspaper articles

Book(s)

Magazine(s)

Radio

Television

Hospital or clinic booklet(s), brochure(s) or similar information piece(s)

Family and/or friends

Other women with breast cancer and/or support groups

Personal physician (primary care or specialist)

Doctor's office nurse

Other (specify) 
13. Please read each of the following statements and circle the number below the response which reflects how much you agree or disagree with the statement. (Circle one number for each statement.)

\begin{tabular}{|c|c|c|c|c|c|c|}
\hline & $\begin{array}{c}\text { Very } \\
\text { strongly } \\
\text { disagree }\end{array}$ & $\begin{array}{l}\text { Strongly } \\
\text { disagree }\end{array}$ & Disagree & Agree & $\begin{array}{l}\text { Strongly } \\
\text { agree }\end{array}$ & $\begin{array}{c}\text { Very } \\
\text { strongly } \\
\text { agree }\end{array}$ \\
\hline $\begin{array}{l}\text { 13a. I got all the information I needed to understand } \\
\text { treatment options for my breast cancer from my } \\
\text { physician and her/his office staff. }\end{array}$ & 0 & 1 & 2 & 3 & 4 & 5 \\
\hline $\begin{array}{l}\text { 13b. I got all the information I needed to make decisions } \\
\text { about treatment for my breast cancer from my } \\
\text { physician and her/his staff. }\end{array}$ & 0 & 1 & 2 & 3 & 4 & 5 \\
\hline $\begin{array}{l}\text { 13c. I got all the information I needed to cope with my } \\
\text { breast cancer from my physician and her/his office staff. }\end{array}$ & 0 & 1 & 2 & 3 & 4 & 5 \\
\hline
\end{tabular}

Your answers to the questions below will help us to better understand the relationship of factors such as age, gender and socioeconomic status to the way breast cancer patients access and use information. Your individual information will be kept confidential.

14. What is your age?

15. What is your gender?

16. What best describes your ethnic/racial background?

17. Is English your primary language?

18. What is your current marital status?

19. What is the highest grade or level of education you have completed? (Mark only one answer.)

20. What is your estimated annual household income?

_ male_female
_ African American/Black
_ American Indian/Aleut/Eskimo
_ Asian/Pacific Islander
_ Caucasian/White
_ Hispanic/Latino
_ Other (specify)

_yes _ no

_ Married/living as married

- Divorced

— Separated

Widowed

_ Single, never married

_ 8th grade or less

— Some high school (grade 9-12)

_ High school diploma or GED

_ Vocational school or some college

_ College degree

_ Professional or graduate school experience

Less than $\$ 15,000$

— $\$ 15,000$ to $\$ 29,999$

— $\$ 30,000$ to $\$ 49,999$

- $\$ 50,000$ to $\$ 74,999$

_ $\$ 75,000$ or more 
Copyright of Journal of Communication in Healthcare is the property of Henry Stewart Publications LLP and its content may not be copied or emailed to multiple sites or posted to a listserv without the copyright holder's express written permission. However, users may print, download, or email articles for individual use. 